\title{
Cost and production performance of a tubular solar still
}

\begin{abstract}
In this paper, the design, fabrication, cost and distilled water production (production) performance of a Tubular Solar Still (TSS) is presented. Since the TSS cover and trough are made of cheap and locally acquisitioned lightweight materials, the TSS can be formed into a desirable size easily. Thus, the weight per unit length is $0.65 \mathrm{~kg} / \mathrm{m}$ and it is expected that the production cost is about $¥ 484 / \mathrm{m} 3$ (åUS $\$ 5 / \mathrm{m} 3$ ). A field experiment on the production performance of the TSS was carried out in the United Arab Emirates and the effects of initial saline water volume (water depth) in the trough on the daily production were examined in terms of the use and management of the TSS. The daily production is inversely proportional to the water depth, as far as the water depth is $0.04 \mathrm{~m}$ or less. The main reason is attributed to the production performance after the evening or sunset due to remaining solar heat (designated as ñproduction inertiaò). It is seen that contribution of the production inertia to the daily production cannot be disregarded and that the water depth is one of key parameters to control the production performance of the TSS.
\end{abstract}

Keyword: Tubular solar still; Daily production; Production inertia 